\title{
COVID-19 during pregnancy: vertical transmission, diagnosis and maternal-fetal complications
}

\author{
Mounir Moukit ${ }^{1 *}$, Assia El Ouardi², Abdellah Babahabib ${ }^{1,3}$, El Mehdi El Hassani ${ }^{1,3}$, \\ Jaouad Kouach ${ }^{1,3}$
}

\begin{abstract}
${ }^{1}$ Department of Obstetrics and Gynecology, Military Training Hospital Mohammed V, Rabat, Morocco
${ }^{2}$ Department of COVID-19, University Hospital Center Hassan II, Fes, Morocco

${ }^{3}$ Faculty of Medicine and Pharmacy, University Mohammed V, Rabat, Morocco
\end{abstract}

Received: 22 May 2020

Accepted: 30 June 2020

\author{
*Correspondence: \\ Dr. Moukit Mounir, \\ E-mail: moukitmounir@yahoo.com
}

Copyright: (c) the author(s), publisher and licensee Medip Academy. This is an open-access article distributed under the terms of the Creative Commons Attribution Non-Commercial License, which permits unrestricted non-commercial use, distribution, and reproduction in any medium, provided the original work is properly cited.

\begin{abstract}
The current pneumonia outbreak of COVID-19 has been declared a pandemic by the World Health Organization on March 11, 2020. With its indiscriminate spread across continents, authors are likely to see women with COVID-19 canvassed across all trimesters of pregnancy. To date, few reports have provided information about this disease in pregnant patients. Authors conducted a literature review to summarize the results concerning intrauterine transmission, diagnostic challenges and maternal-fetal outcomes of pregnant women with COVID-19 pneumonia.
\end{abstract}

Keywords: COVID-19, Diagnosis, Maternal and fetal complications, Pregnancy, Vertical transmission

\section{INTRODUCTION}

In December 2019, a new strain of coronavirus causing coronavirus disease 2019 (COVID-19) was first identified in Wuhan, a mega city with an 11 million population in central China. ${ }^{1}$ Over the ensuing weeks, widespread transmission of severe acute respiratory syndrome coronavirus 2 (SARS-CoV-2), the virus that causes COVID-19, has been reported in all continents. As of April 22, 2020, there are more than 1.714.000 active cases in the world and approximately 182.000 deaths. The epidemiological data showed that most cases had mild symptoms, with the overall case fatality rate of $2.3 \% .^{2}$ Although most human coronavirus infections are mild, the SARS-CoV and Middle East respiratory syndrome coronavirus (MERS-CoV) epidemics of the past two decades were grave; the fatality rate of SARS and MERS among pregnant patients was $25 \%$ and $40 \%$, respectively. ${ }^{3,4}$ While data regarding COVID-19 continues to inform authors understanding of this disease, clinical reports on maternal and neonatal outcomes of pregnant women with SARS-CoV-2 infection are rare and limited to small case series. In this article, authors conducted a literature review of publicly available information to summarize knowledge about the pathogen in this vulnerable population. Vertical transmission, diagnosis and maternal-fetal complications are all reviewed.

\section{VERTICAL TRANSMISSION}

Actually, emerging evidence suggests that vertical transmission is probable. In fact, two reports have published evidence of IgM for SARS-COV-2 in neonatal serum at birth. ${ }^{5,6}$ Since IgM does not cross the placenta, this is likely to represent a neonatal immune response to in utero infection. However, there are no confirmed cases of vertical transmission among the other neonates born to COVID-19 infected mothers, supported by an absence of virus in amniotic fluid, cord blood, placenta swabs and neonatal throat swabs. ${ }^{2,7,8}$ 
Table 1: Fetal complications reported in the literature (case reports have been excluded).

\begin{tabular}{|c|c|c|c|c|c|c|c|c|}
\hline & $\mathbf{n}$ & $\begin{array}{l}\text { Median } \\
\text { gestational age } \\
\text { at birth (weeks) }\end{array}$ & IUFD & $\begin{array}{l}\text { Premature } \\
\text { birth }\end{array}$ & $\begin{array}{l}\text { Low birth } \\
\text { weight }\end{array}$ & $\begin{array}{l}\text { Apgar score } \\
\text { at } 5 \text { minutes }\end{array}$ & $\begin{array}{l}\text { Still } \\
\text { birth }\end{array}$ & $\begin{array}{l}\text { Vertical } \\
\text { transmission }\end{array}$ \\
\hline Li et $\mathbf{a l}^{2}$ & 36 & 38 & $8 \%$ & $22 \%$ & $13 \%$ & 10 & No one & No one \\
\hline Liu et $\mathbf{a l}^{27}$ & 19 & 38 & - & - & No one & $\geq 8$ & No one & No one \\
\hline Breslin et al ${ }^{9}$ & 18 & 37 & No one & $5 \%$ & No one & $\geq 9$ & No one & No one \\
\hline Zhang et $\mathrm{al}^{24}$ & 16 & 38 & \multicolumn{4}{|c|}{$\begin{array}{l}\text { No difference with women without COVID-19 } \\
\text { (comparative study) }\end{array}$} & No one & $\begin{array}{l}\text { No one in } 10 \\
\text { of } 16 \text { neonates }\end{array}$ \\
\hline Yang et $\mathbf{a l}^{26}$ & 13 & 38 & - & - & No one & - & No one & No one \\
\hline Liu et $\mathbf{a l}^{23}$ & 11 & 37 & No one & - & - & $\geq 8$ & No one & - \\
\hline Liu et al ${ }^{17}$ & 10 & 35 & $30 \%$ & $60 \%$ & - & 10 & $10 \%$ & No one \\
\hline Zhu et al $^{22}$ & 9 & 38 & $55 \%$ & $55 \%$ & $22 \%$ & $\geq 8$ & No one & No one \\
\hline Chen et al ${ }^{10}$ & 9 & 38 & $11 \%$ & $44 \%$ & $22 \%$ & $\geq 9$ & No one & $\begin{array}{l}\text { No one in } 6 \text { of } \\
9 \text { neonates }\end{array}$ \\
\hline Yu et $\mathbf{a l}^{25}$ & 7 & 39 & No one & No one & No one & $\geq 9$ & No one & $14 \%$ \\
\hline Chen et al $^{8}$ & 4 & 38 & No one & No one & No one & $\geq 7$ & No one & No one \\
\hline
\end{tabular}

IUFD: Intrauterine fetal distress.

\section{DIAGNOSIS}

Clinical features of COVID-19 are similar to nonpregnant patients (fever during pregnancy or postpartum period, cough, shortness of breath, headache, anosmia). It is important to note that gestational rhinitis, usually affects a fifth of healthy women in late pregnancy and due to estrogen-mediated hyperaemia of the nasopharynx, may mask symptoms of COVID-19 and consequently causing community transmission. In addition, physiologic dyspnea due to increased maternal oxygen demands from heightened metabolism and anemia is common in pregnancy and must be distinguished from a pathologic breathlessness. In a series of 43 COVID-19-positive pregnant women identified over a two-week period, infection was often asymptomatic, supporting a role for universal testing of pregnant women being admitted to the Labor Unit. $^{9}$ Laboratory investigations are not specific. An early study has evaluated the outcome of nine pregnant patients with COVID-19 without any specific underlying diagnosed diseases (all gestational ages $\geq 36$ weeks). Among them, none had leukopenia (perhaps masked by the physiological increased levels of white blood cells during pregnancy) while $56 \%$ had only lymphopenia $\left(<109\right.$ cells/L). ${ }^{10}$ Also, elevated CRP and liver cytolysis were observed in $75 \%$ and $33 \%$ respectively. ${ }^{10}$ The reverse transcriptase polymerase chain reaction (RT-PCR) test for SARS-CoV-2 from respiratory specimens is the gold standard for diagnosis. It is a quantitative test and the determination of viral load is possible. However, a previous report argued that false negatives cases might be common due to low virus titers, sampling at late stage of illness, and inappropriate swabbing sites. ${ }^{10}$ Antigen-antibody detection tests are not validated, and viral culture takes at least 72 hours to cause cytopathic effects in selected cell lines. Chest imaging is used for diagnosis of 2019 novel coronavirus disease, as an important complement to the RT-PCR tests. Predominant radiological appearances are peripheral airspace shadowing on a plain chest radiograph and bilateral, multi-lobar ground-glass opacities or consolidation on computed tomography (CT) scan. ${ }^{11,12}$ The sensitivity, specificity, positive predictive value and negative predictive value of a CT chest in diagnosing this entity are $97 \%, 25 \%, 65 \%$ and $83 \%$ respectively. ${ }^{13}$ In pregnancy, fetal exposure to ionizing radiation during a $\mathrm{CT}$ chest is not associated with increased risk of teratogenicity. ${ }^{14,15}$

\section{MATERNAL COMPLICATIONS}

Compared to SARS and MERS, maternal prognosis during COVID-19 infection appears more promising. ${ }^{4,16}$ Whilst pregnant women are not more susceptible to viral illness, changes to their cardiorespiratory and immune system increase susceptibility to severe infection, particularly in the last trimester. There have been cases reports of women with severe COVID at the time of birth that has required ventilation and extracorporeal membrane oxygenation. ${ }^{17} \mathrm{~A}$ single case report has been published a maternal and intrauterine fetal death, at 30 weeks, attributed to COVID-19. ${ }^{18}$ Recently, Breslin et al. have described a case series of 43 women tested positive for COVID-19 and showed a similar pattern of disease severity to non-pregnant women: $86 \%$ mild, $9.3 \%$ severe and $4.7 \%$ critical, although the sample size was too small to draw a definitive conclusion. ${ }^{9}$ A study has evaluated the risk factors related to the mortality among survivor and non-survivor patients diagnosed with COVID-19. ${ }^{19}$ Authors have stated that sepsis, respiratory failure, acute respiratory distress syndrome, heart failure, septic shock, coagulopathy, acute cardiac injury, and acute kidney injury were significantly higher in non-survivors. In addition, they have shown that the administration of 
corticosteroids in non-survivors was significantly higher than in survivor group. ${ }^{19}$ Given that pregnancy is known to be a hypercoagulable state, and emerging evidence suggests that individuals admitted to hospital with COVID-19 are also hypercoagulable, it follows that infection with COVID-19 is likely to be associated with an increased risk of maternal venousthromboembolism. ${ }^{20,21}$ Also, reduced mobility resulting from isolation increases this risk.

\section{FETAL COMPLICATIONS}

There are currently no data suggesting an increased risk of miscarriage or early pregnancy loss in relation to COVID-19. There are case reports of preterm birth in women with COVID-19, but it is unclear whether this was iatrogenic or spontaneous. Liu et al and Chen et al have reported other complications including fetal distress (23\%), premature rupture of the membrane (7\%), stillbirth (7\%) and low birth weight. ${ }^{10,17}$ Currently, there is no evidence that the virus is teratogenic. It is notable that the majority of reported cases acquired COVID-19 in the last trimester, and there is no data when the infection is acquired in early gestational age. The situation may change and continued monitoring is recommended. Fetal complications reported in the literature are summarized in Table 1. Protracted respiratory compromise increases the risk of fetal growth restriction due to maternal hypoxia. Consequently, fetal monitoring by ultrasound is recommended. Although the data do not suggest a risk of vertical transmission, delayed clamping of the umbilical cord and skin-to-skin contact should be avoided following delivery, extrapolating from recommendations by the Canadian society of obstetricians and gynecologists guidelines for SARS in pregnancy. ${ }^{28}$

\section{CONCLUSION}

Pregnant women are a vulnerable group in SARS-CoV-2 infection. The latest may increase health risks to both mothers and fetus during pregnancy. Efforts should be taken to reduce the infection rate of SARS-CoV-2 during gestational and postpartum period, and more intensive attention should be paid to pregnant patients.

Funding: No funding sources Conflict of interest: None declared

Ethical approval: Not required

\section{REFERENCES}

1. Zhu N, Zhang D, Wang W, Li X, Yang B, Song J, et al. A novel coronavirus from patients with pneumonia in China, 2019. N Engl J Med 2020.

2. Li N, Han L, Peng M, Lv Y, Ouyang Y, Liu K, et al. Maternal and neonatal outcomes of pregnant women with COVID-19 pneumonia: a case-control study. Clin Infect Dis. 2020:In Press.

3. Wong SF, Chow KM, Leung TN, Ng WF, Ng TK, Shek CC, et al. Pregnancy and perinatal outcomes of women with severe acute respiratory syndrome. Am J Obstet Gynecol. 2004;191:292-7.

4. Assiri A, Abedi GR, Al Masri M, Bin Saeed A, Gerber SI, Watson JT. Middle east respiratory syndrome coronavirus infection during pregnancy: a report of 5 cases from Saudi Arabia. Clin Infect Dis. 2016;63:951-3.

5. Dong L, Tian J, He S, Zhu C, Wang J, Liu C, Yang J. Possible vertical transmission of SARS-CoV-2 from an infected mother to her newborn. JAMA. 2020;323(18):1846-8.

6. Zeng H, Xu C, Fan J, Tang Y, Deng Q, Zhang W, et al. Antibodies in infants born to mothers with COVID-19 pneumonia. JAMA. 2020;323(18):18489.

7. Li Y, Zhao R, Zheng S, Chen X, Wang J, Sheng X, et al. Lack of vertical transmission of severe acute respiratory syndrome coronavirus 2, China. Emerg Infect Dis 2020;26(6):1335-6.

8. Chen Y, Peng H, Wang L, Zhao Y, Zeng L, Gao H, et al. Infants born to mothers with a new coronavirus (COVID-19). Frontiers Pediatr. 2020;8:104.

9. Breslin N, Baptiste C, Gyamfi-Bannerman C, Miller $\mathrm{R}$, Martinez R, Bernstein K, et al. COVID-19 infection among asymptomatic and symptomatic pregnant women: Two weeks of confirmed presentations to an affiliated pair of New York City hospitals. Am J Obstet Gynecol MFM. 2020:100118.

10. Chen H, Guo J, Wang C, Luo F, Yu X, Zhang W, et al. Clinical characteristics and intrauterine vertical transmission potential of COVID-19 infection in nine pregnant women: a retrospective review of medical records. Lancet. 2020;395(10226):809-15.

11. Kong W, Argawal PP. Chest imaging appearance of COVID-19 infection. Radiol. 2020;2:e200028.

12. Shi H, Han X, Jiang N, Cao Y, Alwalid O, Gu J, et al. Radiological findings from 81 patients with COVID-19 pneumonia in Wuhan, China: a descriptive study. Lancet Infect Dis. 2020;20(4):42534.

13. Ai T, Yang Z, Hou H, Zhan C, Chen C, Lv W, et al. Correlation of chest CT and RT-PCR testing in coronavirus disease 2019 (COVID-19) in China: a report of 1014 cases. Radiol. 2020:200642.

14. Guidelines for diagnostic imaging during pregnancy and lactation. ACOG Committee Opinion, Number 723, 2017. Available at: https://www.acog.org/Clinical-Guidance-andPublications/Committee-Opinions/Committee-onObstetric-Practice/Guidelines-for-DiagnosticImaging-During-Pregnancy-and-Lactation?IsMobile Set=false. Accessed on $20^{\text {th }}$ February 2020.

15. Smith-Bindman R, Lipson J, Marcus R, Kim KP, Mahesh M, Gould R, et al. Radiation dose associated with common computed tomography examinations and the associated lifetime attributable risk of cancer. Arch Intern Med. 2009;169:2078-86.

16. Wong SF, Chow KM, de Swiet M. Severe acute respiratory syndrome and pregnancy. BJOG. 2003;110:641-2. 
17. Liu Y, Chen H, Tang K, Guo Y. Clinical manifestations and outcome of SARS-CoV-2 infection during pregnancy. J Infect. 2020.pii: S0163-4453(20)30109-2.

18. Karami P, Naghavi M, Feyzi A, Aghamohammadi M, Novin MS, Mobaien A, et al. Mortality of a pregnant patient diagnosed with COVID-19: A case report with clinical, radiological, and histopathological findings. Travel Med Infect Dis. 2020:101665.

19. Zhou F, Yu T, Du R, Fan G, Liu Y, Liu Z, et al. Clinical course and risk factors for mortality of adult inpatients with COVID-19 in Wuhan, China: a retrospective cohort study. Lancet. 2020;395(10229):1054-62.

20. Gynaecologists R. Reducing the risk of venous thromboembolism during pregnancy and the puerperium. Green-top Guideline. 2015;37:1-40.

21. Practical guidance for the prevention of thrombosis and management of coagulopathy and disseminated intravascular coagulation of patients infected with COVID-19, 2020. Available at: https://thrombosisuk. org/ COVID-19-thrombosis.php. Accessed on $7^{\text {th }}$ April 2020.

22. Zhu H, Wang L, Fang C, Peng S, Zhang L, Chang G, et al. Clinical analysis of 10 neonates born to mothers with 2019-nCoV pneumonia. Transl Pediatr. 2020;9(1):51-60.

23. Liu D, Li L, Wu X, Zheng D, Wang J, Yang L, et al. Pregnancy and perinatal outcomes of women with coronavirus disease (COVID-19) pneumonia: a preliminary analysis. Am J Roentgenol. 2020:1-6.

24. Zhang L, Jiang Y, Wei M, Cheng BH, Zhou XC, Li $\mathrm{J}$, et al. Analysis of the pregnancy outcomes in pregnant women with COVID-19 in Hubei Province. Zhonghua Fu Chan Ke Za Zhi. 2020;55:E009.

25. Yu N, Li W, Kang Q, Xiong Z, Wang S, Lin X, et al. Clinical features and obstetric and neonatal outcomes of pregnant patients with COVID-19 in Wuhan, China: a retrospective, single-centre, descriptive study. Lancet Infect Dis. 2020;20(5):559-64.

26. Sun G, Tang F, Peng M, Gao Y, Peng J, Xie H, et al. Clinical features and outcomes of pregnant women suspected of coronavirus disease 2019. Journal of Infection. 2020;81(1):e40-e44.

27. Liu W, Wang J, Li W, Zhou Z, Liu S, Rong Z. Clinical characteristics of 19 neonates born to mothers with COVID-19. Front Med. 2020:1-6.

28. Dashraath P, Jing Lin Jeslyn W, Mei Xian Karen L, et al. Coronavirus Disease 2019 (COVID-19) pandemic and pregnancy. Am J Obstet Gynecol. 2020;222(6):521-31.

Cite this article as: Moukit M, Ouardi AE, Babahabib A, Hassani EME, Kouach J. COVID-19 during pregnancy: vertical transmission, diagnosis and maternal-fetal complications. Int J Reprod Contracept Obstet Gynecol 2020;9:3915-8. 